DOI 10. 18307/2015. 0619

(C) 2015 by Journal of Lake Sciences

\title{
太湖蓝藻水华发生风险区划"
}

张艳会 ${ }^{1,2}$, 李伟峰 ${ }^{2 * *}$, 陈求稳 ${ }^{3}$

(1: 中国科学院南京地理与湖泊研究所流域地理学重点实验室, 南京 210008)

(2: 中国科学院生态环境研究中心城市与区域生态国家重点实验室, 北京 100085)

( 3 : 南京水利科学研究院生态环境研究中心, 南京 210029)

摘 要: 湖泊水华是全世界面临的严重生态环境问题之一, 对人类和生态系统健康都有重大影响. 以太湖为研究区域, 基 于近年的蓝藻水华及水环境监测数据, 结合自组织特征映射神经网络和模糊风险评价方法, 对太湖不同监测点蓝藻水华的 发生风险进行综合评价, 并借助 GIS 地学统计分析方法对全太湖蓝藻水华发生风险进行区划, 绘制太湖蓝藻水华发生风险 区划图. 结果表明:太湖被分为重度风险区、中度风险区、轻度风险区、微风险区, 各风险区基本呈带状分布. 从各风险区面积 来看, 重度风险区、中度风险区、轻度风险区的面积约各占太湖总面积的 $1 / 5$, 而微风险区约占太湖总面积的 $2 / 5$; 从各风 险区位置来看, 重度风险区主要分布在西北部区域, 且从整个湖区来看, 蓝藻水华的发生风险等级自西北到东南依次递 减. 本研究揭示太湖水华灾害风险的空间分布规律, 对支撑水环境监测和水华灾害防治方案的制定具有一定的意义.

关键词: 太湖;蓝藻水华; 风险评价; 风险区划

\section{Algae bloom risk zoning of Lake Taihu}

\section{ZHANG Yanhui ${ }^{1,2}$, LI Weifeng ${ }^{2} \&$ CHEN Qiuwen ${ }^{3}$}

(1: Key Laboratory of Watershed Geographic Sciences, Nanjing Institute of Geography and Limnology, Chinese Academy of Sciences, Nanjing 210008, P. R. China)

(2: State Key Laboratory of Urban and Regional Ecology, Research Center for Eco-Environmental Sciences, Chinese Academy of Sciences, Beijing 100085 , P. R. China)

(3: Eco-Environmental Research Center, Nanjing Hydraulic Research Institute, Nanjing 210029, P. R. China)

\begin{abstract}
Water bloom is one of the most serious ecological environmental problems, which threaten the health of human being and local ecosystems. In this study, we took Lake Taihu in China as the study area, and accessed the occurrence risk of blue-green algae blooms comprehensively based on the individual site, combining self-organizing feature map neural network and fuzzy risk assessment method. Then We exploited the blue-green algae bloom risk zoning and draw the zoning map based on the individual site specific blue-green algae bloom risk assessment through GIS geological statistics analysis method. The assessment results showed that the whole Lake Taihu was divided into four risk zones: sever zone, moderate zone, mild zone and none risk zone, distributing along the aclinic aspect of the slope from northwest to southeast. As a whole, 3/5 of Lake Taihu faced blue-green algae bloom occurrence risk and only less than 2/5 lake area was little or no risk. The blue-green algae bloom occurrence risk presented an obvious mitigation from the northwest to the southeast, where the most sever risk zone was on the north-west. In summary, this study revealed the spatial distribution of blue-green algae bloom occurrence and these method and result would be helpful to support efficient blue-green algae bloom monitoring and risk management.
\end{abstract}

Keywords: Lake Taihu; blue-green algae bloom; risk assessment; risk zoning

目前, 湖泊蓝藻水华是各个国家面临的重大环境问题之一. 就我国而言, 由于湖泊富营养化程度的趋势不 断加重 ${ }^{[1]}$, 湖泊蓝藻水华的暴发越来越频繁, 暴发面积也在不断增加, 比如太湖, 自 2007 年以来, 其蓝藻水华发

* 中国科学院科技服务网络计划 (STS) 资助. 2014-12-10 收稿; 2015-02-03 收修改稿. 张艳会 (1984 ), 女, 博士 研究生;E-mail:xiaohuizi1984@126. com.

** 通信作者;E-mail:li.wf@ rcees. ac. cn. 
生的典型个例越来越多、范围逐年扩大、强度逐渐增大, 造成重大危害 ${ }^{[2-6]}$. 鉴于此, 国内外的学者进行了大量 研究, 其中, 大部分集中在蓝藻水华暴发机理和水华预测等方面 ${ }^{[7-13]}$. 研究表明, 风险区划是在可能避免和减轻 自然灾害的措施中最简便有效的方法 ${ }^{[14]}$. 自 20 世纪中期, 风险区划在美国、日本等国家均有较好的发展. 1980s 后期, 我国也相继开展洪水、地震、干旱等自然灾害风险区划研究 ${ }^{[15-18]}$. 然而, 湖泊蓝藻水华在科学研究的基础上进 行发生风险区划的研究还较少, 刘聚涛等基于突变理论开展太湖蓝藻危险性分区评价 ${ }^{[19]}$. 因此, 为了有效地减少 蓝藻水华的发生及其带来的影响,非常有必要对蓝藻水华发生风险进行综合评价与科学区划.

蓝藻水华的发生是营养盐、水温、风速等气象条件以及湖泊形态等众多因素共同作用的结果, 目前, 虽 然关于蓝藻水华的暴发机理已经开展较多研究, 但不同影响因素与蓝藻水华之间的相互影响机制尚未有明 确定论. 因此, 通过大量观察和监测数据进行统计分析是分析这种多因素、非线性复杂过程的有效手段. 人 工神经网络是一种非常实用有效的非线性统计分析方法, 对多变量影响的复杂系统过程分析具有很大优 势, 其可根据大量数据信息, 通过自适应训练学习, 揭示不同变量之间的相互响应机制 ${ }^{[20-21]}$. 由于蓝藻水华 的发生机制复杂, 蓝藻水华是否暴发、暴发的范围和强度具有很大的不确定性, 即水华发生风险的不确定 性. 因此, 要较为全面地揭示水华发生的综合风险, 必须要清楚地认识各种不确定性. 模糊风险评价法是基 于信息分配理论 ${ }^{[22]}$ 的一种综合评价方法, 它运用内一外集模型 ${ }^{[23]}$ 计算出可能性-概率模糊风险, 即某一事件 以某一概率发生的可能性大小, 其可相对精确地表达风险的不确定性. 本研究结合自组织特征映射神经网 络和模糊风险评价方法, 深人分析太湖蓝藻水华发生风险的各种不确定性, 在此基础上, 综合评价太湖不同 点位的水华发生风险, 并结合 GIS 地统计空间分析方法, 绘制全太湖蓝藻水华发生风险区划图. 本研究揭示 太湖蓝藻水华灾害风险的空间分布规律, 对支撑水环境监测和水华灾害防治方案的制定具有一定的意义.

\section{1 研究区域和数据}

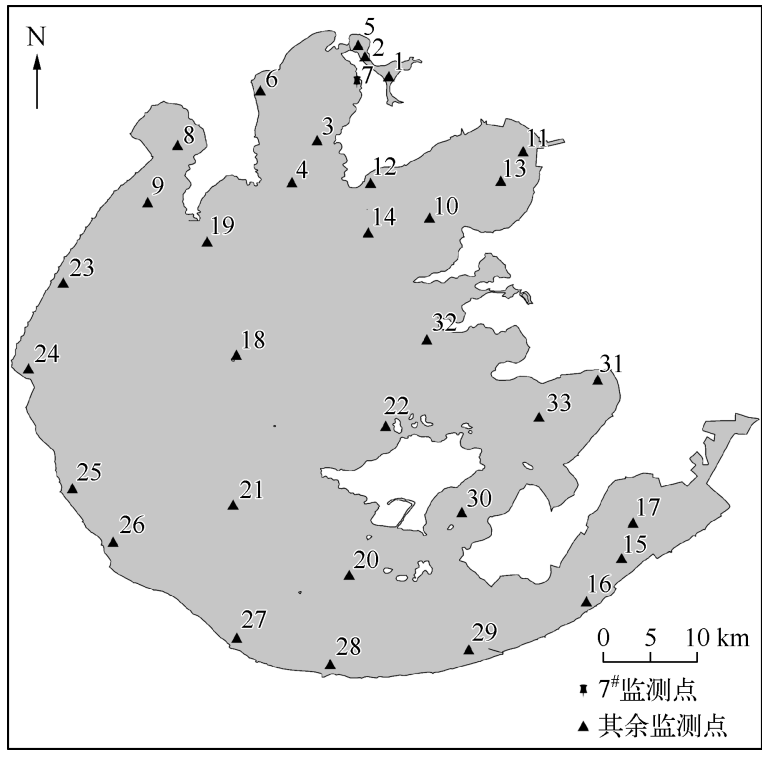

图 1 太湖监测站点分布

Fig. 1 Distribution of monitoring sites in Lake Taihu

太湖 $\left(30^{\circ} 55^{\prime} \sim 31^{\circ} 34^{\prime} \mathrm{N}, 119^{\circ} 53^{\prime} \sim\right.$ $120^{\circ} 36^{\prime} \mathrm{E}$ ) 地处长江三角洲的南部, 面积 $2338 \mathrm{~km}^{2}$, 平均水深不到 $2 \mathrm{~m}^{[4]}$. 该地属于亚热 带季风气候类型, 四季分明. 20 世纪后期太湖 蓝藻水华问题日益突出, 是国务院指定重点治 理的富营养化水域之一. 本研究所采用的水质 数据是 $2008-2010$ 年每月 1 次的监测数据, 覆盖全太湖的 33 个监测点 (图 1), 水质监测 指标包括叶绿素 a (Chl. a) 浓度、总氮 ( TN) 浓 度、总磷 $(\mathrm{TP})$ 浓度、高锰酸盐指数 $\left(\mathrm{COD}_{\mathrm{Mn}}\right)$ 和 温度等 ${ }^{[24]}$, 以及 2010 年 4-12 月对太湖梅梁 湾湖区每天进行的有、无蓝藻水华发生的现场 调查数据.

\section{2 研究方法}

本研究采用自组织特征映射神经网络和 模糊风险评价方法定量分析太湖不同监测点 蓝藻水华的发生风险, 并结合 GIS 地学统计法 进行分析, 对太湖蓝藻水华发生风险区划 (图 2).

本研究的总体分析步骤是: (1) 基于 2008-2010 年 4-12 月太湖不同监测点的水环境及蓝藻水华监测 数据, 运用自组织特征映射神经网络对不同监测站点的蓝藻水华程度进行聚类分析及验证. 研究表明, 蓝藻 水华的发生主要受营养盐、温度等环境要素共同影响 ${ }^{[25]}$. 同时, 鉴于 Chl. a 浓度与蓝藻的关系, Chl. a 浓度 被看作是蓝藻生物量的替代色素 ${ }^{[26]}$, 因而, 选取 5 个与水华暴发密切相关的因子作为输人层指标, 即 Ch. a、 


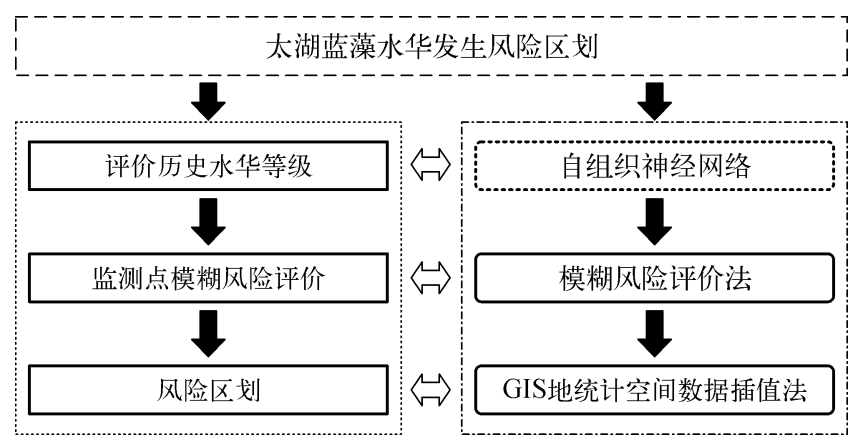

图 2 技术路线图

Fig. 2 The technique route

$\mathrm{TN} 、 \mathrm{TP} 、 \mathrm{COD}_{\mathrm{Mn}}$ 、水温, 其中, Chl. a 和 $\mathrm{COD}_{\mathrm{Mn}}$ 被选作蓝藻水华发生程度的指示因子, $\mathrm{TN} 、 \mathrm{TP}$ 是蓝藻水华发生的 主要营养盐因素, 水温是蓝藻水华发生的关键性气象因素, 所选取的网络结构是 $2 \times 3$; (2) 基于单个监测点 的蓝藻水华特征评价结果, 运用模糊风险评价法对每个监测点的蓝藻水华发生风险进行综合评价; (3) 借 助 GIS 平台, 运用地统计空间数据插值方法, 对全太湖进行蓝藻水华发生风险评价, 并根据水华风险强度等 级特征进行分区. 最后, 绘制太湖蓝藻水华发生风险分布图.

\section{3 研究结果}

\section{1 蓝藻水华历史发生情况评价结果}

根据自组织特征映射神经网络的聚类分析结 果, 太湖不同监测站点的蓝藻水华发生情况, 可分 为 4 类:无水华、轻度水华、中度水华、重度水华. 经过综合分析, 不同程度蓝藻水华, 各个响应变量 的阈值范围表明,从无水华到重度水华各参数基 本呈现递增的趋势, 同时有 2 个较大的转折点 (表 1):1) 重度水华的水温却较中度水华的水温低. 根据现场的考察发现重度水华大多是片状水华， 这可能跟风的聚集作用有关, 也与张成成等的研 究结果一致, 即较高的 Chl. a 浓度可能与风力和 水动力造成的蓝藻积聚有关 ${ }^{[27]} ; 2$ ) 中度水华时 $\mathrm{TN}$ 浓度较低, 可能与中度水华时 TN 消耗量达到 较大有关.

太湖北部小湾里监测点 $2008-2010$ 年不同 监测时期蓝藻水华的风险特征值见表 2. 其中, 水 华风险值是依据 Chl. a 浓度经过标准量化后的结 果, 其中, $(0,3]$ 为无水华, $(3,5]$ 为轻度水华, $(5,7]$ 为中度水华, $>7$ 为重度水华.

对于上述聚类结果, 用 2010 年的监测数据 (是否发生水华的现场记录) 对水华特征聚类结 果进行精度验证,无水华分类精度最高, 达 90\% 以上, 轻度水华分类精度接近 $80 \%$, 中度和重度 水华的分类精度也都超过 $60 \%$ 。
表 1 各程度蓝藻水华所表示变量的范围

Tab. 1 Range of different variables for different algae bloom degrees

\begin{tabular}{cccccc}
\hline 水华程度 & $\begin{array}{c}\text { 水温/ } \\
{ }^{\circ} \mathrm{C}\end{array}$ & $\begin{array}{c}\mathrm{TN} / \\
(\mathrm{mg} / \mathrm{L})\end{array}$ & $\begin{array}{c}\mathrm{TP} / \\
(\mathrm{mg} / \mathrm{L})\end{array}$ & $\begin{array}{c}\mathrm{COD}_{\mathrm{Mn}} / \\
(\mathrm{mg} / \mathrm{L})\end{array}$ & $\begin{array}{c}\mathrm{Chl} . \mathrm{a} / \\
(\mu \mathrm{g} / \mathrm{L})\end{array}$ \\
\hline 无水华 & 22.53 & 2.19 & 0.05 & 3.56 & 14.13 \\
轻度水华 & 22.62 & 2.66 & 0.10 & 5.02 & 35.57 \\
中度水华 & 28.64 & 2.03 & 0.10 & 5.45 & 42.25 \\
重度水华 & 25.53 & 3.33 & 0.19 & 9.35 & 120.09 \\
\hline
\end{tabular}

表 2 小湾里监测点的聚类结果

Tab. 2 SOMF clustering result of the Xiaowanli site

\begin{tabular}{cccccc}
\hline $\begin{array}{c}\text { 水温/ } \\
{ }^{\circ} \mathrm{C}\end{array}$ & $\begin{array}{c}\mathrm{TN} / \\
(\mathrm{mg} / \mathrm{L})\end{array}$ & $\begin{array}{c}\mathrm{COD}_{\mathrm{Mn}} / \\
(\mathrm{mg} / \mathrm{L})\end{array}$ & $\begin{array}{c}\mathrm{TP} / \\
(\mathrm{mg} / \mathrm{L})\end{array}$ & $\begin{array}{c}\mathrm{Chl} . \mathrm{a} / \\
(\mu \mathrm{g} / \mathrm{L})\end{array}$ & $\begin{array}{c}\text { 水华 } \\
\text { 风险值 }\end{array}$ \\
\hline 25.9 & 2.66 & 4.84 & 0.05 & 12.6 & 3.1 \\
21.9 & 4.13 & 6.69 & 0.12 & 24.4 & 3.8 \\
21.2 & 1.07 & 5.20 & 0.10 & 30.0 & 4.1 \\
20.5 & 4.18 & 4.13 & 0.07 & 38.0 & 4.5 \\
18.2 & 1.89 & 6.05 & 0.11 & 60.6 & 4.8 \\
27.8 & 1.25 & 5.90 & 0.13 & 33.6 & 5.6 \\
30.0 & 1.56 & 6.15 & 0.05 & 53.0 & 6.7 \\
22.1 & 3.41 & 9.92 & 0.21 & 121.0 & 8.7 \\
26.5 & 3.37 & 12.40 & 0.24 & 168.0 & 9.8 \\
15.4 & 7.62 & 17.90 & 0.61 & 255.0 & 9.9 \\
\hline
\end{tabular}




\section{2 太湖蓝藻水华发生风险评价结果}

基于自组织特征映射神经网络的水华特征聚类分析结果, 应用模糊风险评价方法, 对太湖不同监测点 蓝藻水华发生风险的不确定性进行定量分析. 以太湖北部湖区的监测点小湾里为例, 对评价结果进行分析. 小湾里的可能性风险概率见表 3.

发生轻度水华的各种概率的可能性都有, 只是可能性不同, 值越大可能性就越大 (表 3 ). 可能性概率风 险表达概率的可靠性, 有利于风险表达和分析, 对于水华这个复杂的系统, 风险这么表达更有利于水华的防 治. 因此, 高概率不意味着高可能性, 低概率也不意味着低可能性. 如发生中度水华的概率为 0.2 的可能性 为 1 , 而概率为 0.3 的可能性为 0.4 . 由此可知, 可能性概率风险, 相对准确地表述了水华的发生风险.

表 3 小湾里监测点的可能性风险概率*

Tab. 3 Possibility-probability risk evaluation of cyanobacteria-dominant bloom in the Xiaowanli site

\begin{tabular}{|c|c|c|c|c|c|c|c|c|c|c|c|}
\hline \multirow{3}{*}{$\pi_{I_{j}}\left(p_{k}\right)$} & \multicolumn{11}{|c|}{ 概率 } \\
\hline & $p_{0}$ & $p_{1}$ & $p_{2}$ & $p_{3}$ & $p_{4}$ & $p_{5}$ & $p_{6}$ & $p_{7}$ & $p_{8}$ & $p_{9}$ & $p_{10}$ \\
\hline & 0 & 0.1 & 0.2 & 0.3 & 0.4 & 0.5 & 0.6 & 0.7 & 0.8 & 0.9 & 1.0 \\
\hline$I_{1}$ & 0 & 0.3 & 0.4 & 0.5 & 0.6 & 1 & 0.2 & 0 & 0 & 0 & 0 \\
\hline$I_{2}$ & 0.2 & 0.3 & 1 & 0.4 & 0.3 & 0 & 0 & 0 & 0 & 0 & 0 \\
\hline$I_{3}$ & 0.4 & 1 & 0.3 & 0.1 & 0 & 0 & 0 & 0 & 0 & 0 & 0 \\
\hline$I_{4}$ & 0 & 0.1 & 1 & 0.1 & 0 & 0 & 0 & 0 & 0 & 0 & 0 \\
\hline
\end{tabular}

$* \pi_{I_{j}}\left(p_{k}\right)$ 代表可能性概率风险, 即水华以某概率发生的可能性, $p$ 为水华发生的概率, $I$ 为水华的程度区间, $I_{1}$ 为轻度水 华, $I_{2}$ 为中度水华, $I_{3} 、 I_{4}$ 为重度水华, $\pi_{I_{j}}\left(p_{k}\right)=0.6$ 的含义就是该监测点发生轻度水华的概率为 0.4 的可能性为 0.6 .

表 42010 年梅梁湾蓝藻水华调查结果

Tab. 4 Investigation results of blue-green algae bloom of Meiliang Bay, 2010

\begin{tabular}{crrrrc}
\hline 月份 & $\begin{array}{c}\text { 调查 未发现水华 } \\
\text { 次轻度水华 } \\
\text { 次数 }\end{array}$ & $\begin{array}{c}\text { 中度水华 } \\
\text { 次数 }\end{array}$ & $\begin{array}{c}\text { 重度水华 } \\
\text { 次数 }\end{array}$ & \begin{tabular}{c} 
数 \\
\hline 4
\end{tabular} \\
\hline & 5 & 5 & 0 & 0 & 0 \\
5 & 23 & 22 & 1 & 0 & 0 \\
6 & 30 & 18 & 12 & 0 & 0 \\
7 & 26 & 0 & 22 & 3 & 1 \\
8 & 29 & 0 & 19 & 10 & 0 \\
9 & 28 & 0 & 20 & 8 & 0 \\
10 & 19 & 1 & 10 & 8 & 0 \\
11 & 8 & 0 & 7 & 1 & 0 \\
12 & 2 & 0 & 2 & 0 & 0 \\
总次数 & 170 & 46 & 93 & 30 & 1 \\
各程度水 & & 0.27 & 0.54 & 0.18 & 0.01 \\
华所占比重 & & & & & \\
\hline
\end{tabular}

为了检验水华风险评价结果的可靠 性, 对其进行验证. 2010 年梅梁湾 (小湾里 监测点所在湖区) 蓝藻水华现场调查的结 果见表 4. 其中, 轻度水华是颗粒状蓝藻水 华, 中度水华是条状蓝藻水华, 重度水华 是片状蓝藻水华.

梅梁湾发生轻度、中度和重度水华的 概率分别为 $0.54 、 0.18$ 和 0.01 (表 4 ). 发 生轻度、中度和重度蓝藻水华可能性为 1 的概率分别为 $0.5 、 0.2 、 0.1$ 或者 0.2 (表 3 ), 对比可知, 评价结果和调查结果基本 一致. 因此, 通过模糊风险评价方法, 不仅 可以揭示水华是否发生, 还能进一步定量 地揭示不同强度水华发生的概率及其可 能性.

最后, 综合蓝藻水华发生的这些不确 定性, 计算每个监测点的水华发生风险, 即在给定可能性水平之上各种可能发生 概率的数学期望值, 小湾里监测点水华发生的模糊风险值见表 5(黑体). 同理, 计算出太湖其它 32 个监测点 的模糊风险值 (表 5).

风险值为该监测点发生水华的综合程度, 值越大说明发生水华的程度越严重, 风险越大 (表 5 ). 其中, $\alpha$ 是截集的水平, 表示风险发生的可能性, $\alpha$ 越高, 蓝藻水华发生的可能性越大, 对应的发生概率越靠近真实情 况, 不确定性就越低, 本研究选取 0.5 和 0.75 两种可能性水平进行模糊风险评价分析. 保守风险值指以低 概率发生的风险, 而冒险风险值是以高概率发生的风险. 保守风险值普遍高于冒险风险值 (表 5 ), 这是因为 
高概率的灾害事件发生的强度比较小, 风险也较小, 而低概率灾害事件发生的强度比较大, 风险也较大. 另 外, $\alpha$ 为 0.5 时的保守风险值和冒险风险值的差值大于 $\alpha$ 为 0.75 时的差值, 差值越大说明可靠性越低, 可信 任度越差. 当 $\alpha$ 达到一定水平时, 发生的概率就不再改变. 保守风险值就会和冒险风险值合二为一. 在本研 究中, 当 $\alpha$ 为 0.75 时, 保守风险值和冒险风险值就合二为一了. 保守风险值和冒险风险值具有不同的意义, 短期的资源规划和保护以及投资可参考冒险风险值，而长期的水资源规划、投资、保护可参考保守风险值. 鉴于 $\alpha$ 的含义与冒险风险值和保守风险值内涵的差别, 选取 $\alpha$ 为 0.75 时的风险值进行全湖区风险插值和 风险区划.

表 5 太湖湖区所有监测点的模糊风险值

Tab. 5 Fuzzy risk evaluation of 33 sites in Lake Taihu

\begin{tabular}{|c|c|c|c|c|c|c|c|c|c|}
\hline \multirow{3}{*}{ 监测点 } & \multicolumn{4}{|c|}{$\alpha$ 水平 } & \multirow{3}{*}{ 监测点 } & \multicolumn{4}{|c|}{$\alpha$ 水平 } \\
\hline & \multicolumn{2}{|c|}{0.5} & \multicolumn{2}{|c|}{0.75} & & \multicolumn{2}{|c|}{0.5} & \multicolumn{2}{|c|}{0.75} \\
\hline & $\begin{array}{c}\text { 保守 } \\
\text { 风险值 }\end{array}$ & $\begin{array}{c}\text { 冒险 } \\
\text { 风险值 }\end{array}$ & $\begin{array}{l}\text { 保守 } \\
\text { 风险值 }\end{array}$ & $\begin{array}{c}\text { 冒险 } \\
\text { 风险值 }\end{array}$ & & $\begin{array}{l}\text { 保守 } \\
\text { 风险值 }\end{array}$ & $\begin{array}{c}\text { 冒险 } \\
\text { 风险值 }\end{array}$ & $\begin{array}{c}\text { 保守 } \\
\text { 风险值 }\end{array}$ & $\begin{array}{c}\text { 冒险 } \\
\text { 风险值 }\end{array}$ \\
\hline 1 & 5.1 & 5.1 & 5.1 & 5.1 & 18 & 4.6 & 4.6 & 4.6 & 4.6 \\
\hline 2 & 6.0 & 6.0 & 6.0 & 6.0 & 19 & 6.8 & 6.4 & 6.9 & 6.9 \\
\hline 3 & 6.8 & 6.8 & 6.8 & 6.8 & 20 & 6.2 & 6.2 & 6.2 & 6.2 \\
\hline 4 & 6.1 & 6.1 & 6.1 & 6.1 & 21 & 4.5 & 4.5 & 4.5 & 4.5 \\
\hline 5 & 6.1 & 6.0 & 5.9 & 5.9 & 22 & 2.7 & 2.7 & 2.7 & 2.7 \\
\hline 6 & 6.2 & 6.2 & 6.3 & 6.3 & 23 & 5.7 & 6.2 & 6.1 & 6.1 \\
\hline 7 & 6.5 & 6.0 & 6.0 & 6.0 & 24 & 4.5 & 6.2 & 6.3 & 6.3 \\
\hline 8 & 5.6 & 5.4 & 5.6 & 5.6 & 25 & 5.9 & 5.9 & 5.9 & 5.9 \\
\hline 9 & 7.0 & 6.5 & 6.7 & 6.7 & 26 & 6.4 & 6.6 & 6.7 & 6.7 \\
\hline 10 & 4.7 & 4.7 & 4.7 & 4.7 & 27 & 5.2 & 5.2 & 5.2 & 5.2 \\
\hline 11 & 4.5 & 4.8 & 4.8 & 4.8 & 28 & 5.8 & 5.8 & 5.8 & 5.8 \\
\hline 12 & 5.6 & 5.6 & 5.6 & 5.6 & 29 & 2.6 & 2.6 & 2.6 & 2.6 \\
\hline 13 & 2.8 & 2.8 & 2.8 & 2.8 & 30 & 2.1 & 2.1 & 2.1 & 2.1 \\
\hline 14 & 4.4 & 4.4 & 4.4 & 4.4 & 31 & 2.2 & 2.2 & 2.2 & 2.2 \\
\hline 15 & 4.0 & 4.0 & 4.0 & 4.0 & 32 & 2.3 & 2.3 & 2.3 & 2.3 \\
\hline 16 & 2.2 & 2.2 & 2.2 & 2.2 & 33 & 2.5 & 2.5 & 2.5 & 2.5 \\
\hline 17 & 5.0 & 5.1 & 5.3 & 5.3 & & & & & \\
\hline
\end{tabular}

\section{3 太湖蓝藻水华发生风险区划}

鉴于单个监测点的风险不能直观地反映太湖水华风险情况, 根据表 5 各监测点的风险评价结果, 运用 GIS 地统计空间数据插值方法对太湖整个湖区进行蓝藻水华发生风险插值. 根据不同程度水华产生的影响 和太湖的实际特征, 借助 GIS 工具, 绘制出整个湖区的风险分布图, 太湖被分为 4 个风险区 (图 3 ): 微风险 区、轻度风险区、中度风险区、重度风险区、其风险区间分别为 $(0,3] 、(3,5] 、(5,6] 、>6$.

从风险区划图 (图 3 ) 可以发现, 各风险区基本呈带状分布. 从位置来看, 重度风险区和中度风险区位于 太湖西北部区域, 轻度风险区和微风险区位于东南部区域. 就整个太湖而言, 从西北到东南风险呈现逐渐降 低的趋势. 从面积来看, 重度风险区、中度风险区和轻度风险区约占太湖总面积的 $60 \%$, 微风险区约占太湖 总面积的 $40 \%$, 总的来说, 整个太湖蓝藻水华暴发风险相对较大的区域约占 $60 \%$, 说明目前太湖蓝藻水华暴 发的风险较大.

\section{4 结论}

针对蓝藻水华暴发的复杂性和不确定性, 本文运用自组织特征映射神经网络和模糊风险评价方法定量 分析太湖近几年蓝藻水华发生的风险特征. 运用自组织特征映射神经网络, 分析蓝藻水华与不同影响因素 的相互响应关系, 对蓝藻水华发生情况进行自组织聚类, 避免人为判断的主观误差. 运用模糊风险评价方法 


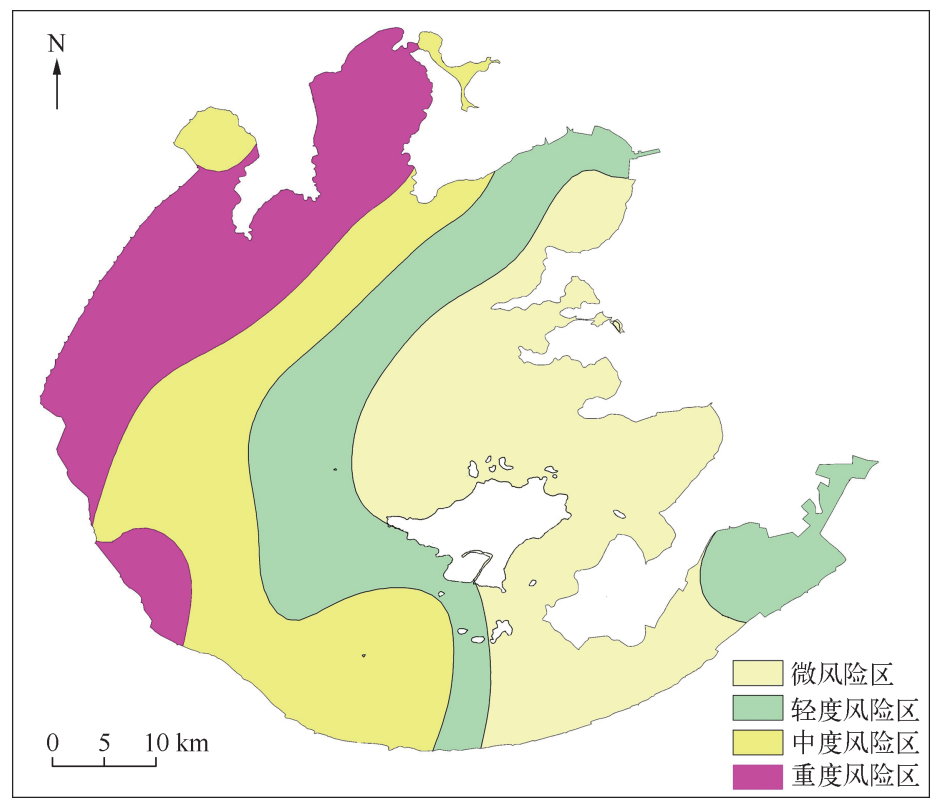

图 3 太湖蓝藻水华发生风险区划

Fig. 3 Regionalization of the occurrence risk of blue-green algae blooms in Lake Taihu

来全面地分析不同程度蓝藻水华发生的概率及可能性, 进而定量地揭示水华发生的不确定性, 以此为基础 的水华风险综合评价能够更加真实地反映太湖水华特征. 最后, 通过对太湖蓝藻水华发生风险的区划, 能够 从全湖大空间尺度上, 直接揭示水华发生风险的空间分布特征. 对水华监测、预警和风险管理具有一定的支 撑作用, 可指导水华防治过程中把资源重点投人到最需要的地方, 从而提高水环境管理的效率, 降低运行 成本.

\section{5 参考文献}

[ 1 ] 朱广伟. 太湖富营养化现状及原因分析. 湖泊科学,2008,20 (1):21-26. DOI 10. 18307/2008. 0103 .

[ 2 ] 商兆堂,任 健,秦铭荣等.气候变化与太湖蓝藻暴发的关系.生态学杂志,2010,29(1):55-61.

[ 3 ] 秦伯强, 王小冬, 汤祥明等. 太湖富营养化与蓝藻水华引起的饮用水危机一一原因与对策. 地球科学进展, 2007, 22 (9) :896-906.

[ 4] 秦伯强,胡维平,陈伟民等. 太湖水环境演化过程与机理. 北京:科学出版社,2004.

[ 5] 黄渏平.太湖水环境及其污染控制. 北京:科学出版社,2001.

[6] 孔繁翔, 胡维平, 谷孝鸿等. 太湖梅梁湾 2007 年蓝藻水华形成及取水口污水团成因分析与应急措施建议. 湖泊科 学,2007,19(4):357-358. DOI 10. 18307/2007.0401.

[ 7 ] 张宁红,黎 刚,郁建桥等. 太湖蓝藻水华暴发的主要特征初析. 中国环境监测, 2009,25(1):71-74.

[ 8 ] 马荣华,孔繁翔,段洪涛等. 基于卫星遥感的太湖蓝藻水华时空分布规律认识. 湖泊科学, 2008,20(6):687-694. DOI 10. 18307/2008.0605.

[ 9 ] 夏 健,钱培东,朱 玮. 2007 年太湖蓝藻水华提前暴发的气象成因探讨. 气象科学,2009,29(4):531-535.

[10］刘聚涛,杨永生,高俊峰.太湖蓝藻水华分级及其时空变化. 长江流域资源与环境,2011,20(2): 156-160.

[11] 孔繁翔,高 光. 大型浅水富营养化湖泊中蓝藻水华形成机理的思考. 生态学报,2005,25(3):589-595.

[12] 孔繁翔, 马荣华, 高俊峰等. 太湖蓝藻水华的预防、预测和预警的理论与实践. 湖泊科学, 2009,21(3):314-328. DOI 10. $18307 / 2009.0302$.

[13] 孔繁翔,曹焕生, 谭 啸. 水华蓝藻复苏的研究进展与水华预测. 环境监控与预警, 2010,2 (1):1-4. 
[14] 黄崇福,张俊香,陈志芬等. 自然灾害风险区划图的一个潜在发展方向. 自然灾害学报,2004,13(2):9-15.

[15] 魏建波,赵文吉,关鸿亮等. 基于 GIS 的区域干旱灾害风险区划研究以武陵山片区为例. 灾害学, 2015,30(1): 198-204.

[16] 殷坤龙,朱良峰. 滑坡灾害空间区划及 GIS 应用研究. 地学前缘,2001,8(2):279-284.

[17] 周成虎,万 庆,黄诗峰. 基于 GIS 的洪水灾害风险区划研究. 地理学报,2000,55(1):15-24.

[18］张俊香,李平日,黄光庆等. 基于信息扩散理论的中国沿海特大台风暴潮灾害风险分析. 热带地理,2007,27(1): 11-14.

[19] 刘聚涛, 高俊峰, 姜加虎等. 基于突变理论的太湖蓝藻水华危险性分区评价. 湖泊科学, 2010,22 (4):488-494. DOI 10. $18307 / 2010.0403$.

[20] 陈求稳. 模式自组在水生生态数据分析中的应用一一太湖富营养化事例分析. 水利学报,2001,(6):8-13.

[21］飞思科技产品研发中心. 神经网络理论与 Matlab7 实现. 北京: 电子工业出版社,2005:44.

[22] 黄崇福. 自然灾害风险评价:理论与实践. 北京:科学出版社,2005:130-134.

[23] 张俊香. 新一代自然灾害风险区划原理与方法研究——以地震灾害为例 [学位论文]. 北京: 北京师范大学,2005: 21-29.

［24］黄翔飞,陈伟民,蔡启铭. 湖泊生态调查与分析. 北京: 中国标准出版社, 1999 .

[25] 马健荣,邓建明,秦伯强等. 湖泊蓝藻水华发生机理研究进展. 生态学报, 2013,33(10):3020-3030.

[26] 马荣华, 孔维娟, 段洪涛等. 基于 MODIS 影像估测太湖蓝藻暴发期藻蓝素含量. 中国环境科学, 2009, 29(3): 254-260.

[27] 张成成,陈求稳,徐 强等. 基于支持向量机的太湖梅梁湾叶绿素 a 浓度预测模型. 环境科学学报, 2013,33(10): 2856-2861. 